\title{
Physical work conditions and perceived health problems among informal automobile artisans
}

\author{
Funmilayo Juliana Afolabi ${ }^{\mathrm{a}, \mathrm{b}, \mathrm{c}, *}$, Paul de Beer ${ }^{\mathrm{a}, \mathrm{b}}$ and Joke A. Haafkens ${ }^{\mathrm{a}}$ \\ ${ }^{a}$ Amsterdam Institute for Advanced Labour Studies and Hugo Sinzheimer Institute (AIAS-HSI), \\ University of Amsterdam, Amsterdam, The Netherlands \\ ${ }^{\mathrm{b}}$ Amsterdam Institute for Social Sciences Research (AISSR), University of Amsterdam, Amsterdam, \\ The Netherlands \\ ${ }^{\mathrm{c}}$ Institute for Entrepreneurship and Development Studies (IFEDS), Obafemi Awolowo University, Ile-Ife, Nigeria
}

Received 29 January 2020

Accepted 17 February 2021

\begin{abstract}
.
BACKGROUND: Automobile car repair requires intensive activities. Several studies have described different work characteristics of automobile artisans' work. However, the effects of physical work conditions (PWC) on worker health outcomes are largely unknown.

OBJECTIVE: This study aimed to explore which of the PWC have high negative impact on worker's health outcomes, and whether the same conditions affected both illnesses and injuries.

METHODS: A cross-sectional design and a multistage method were used to randomly select 632 workers. A structured self-reported questionnaire was used to obtain information on dependent variables (illness/injuries) and independent variables (PWC). The results were analysed using the chi-square test and logistic regression analysis, while controlling for occupation. RESULTS: Workers who manually lifted heavy items or orally sucked petrol regularly reported illnesses and injuries. Long work experience and long working hours were significantly associated with illness, whereas prolonged standing was significantly related to injuries. Contrary to our initial expectation, workers who regularly worked at $2 \mathrm{~m}$ or higher above the ground level tended to report less illness and injury.

CONCLUSIONS: PWCs were more significantly related to work-related illnesses than injuries. Therefore, interventional programs for automobile artisans should focus on the PWC that increase worker vulnerability to work-related illnesses.
\end{abstract}

Keywords: Injury, illness, worker, developing country

\section{Introduction}

There is abundant evidence that unfavourable work conditions can adversely impact workers' health [1]. For instance, unfavourable physical work conditions

\footnotetext{
*Address for correspondence: Funmilayo Juliana Afolabi, Amsterdam Institute for Advanced Labour Studies and Hugo Sinzheimer Institute (AIAS-HSI), University of Amsterdam, Nieuwe Achtergracht 166, 1018 WV, Amsterdam, The Netherlands. Tel.: +31621458554; +2348033171946; E-mails: funmi femifolabi@gmail.com; F.J.Afolabi@uva.nl.
}

(PWC), such as monotonous and repetitive arm movements, awkward body postures, prolonged standing, working with arms above shoulder height, working for long hours, and lifting heavy objects $[2,3]$ have a strong negative association with general health $[4,5]$. Moreover, high chemical exposure or heavy physical workload is associated with cardiovascular diseases and musculoskeletal symptoms, respectively $[5,6]$. Persaud and Williams [7] found that long working hours of more than 8 hours per day or 40 hours per week were associated with increased risk of injuries 
and illnesses. In essence, working long hours potentially exposes workers to numerous physical and chemical hazards $[7,8]$.

The effect of PWC on workers' health in highincome countries [9], where approximately $90 \%$ of the working population is formally employed, has been evaluated in many previous studies [10]. However, relatively little is known about the relationship between PWC and workers' health in developing countries, where approximately $80 \%$ of the working population is employed in the informal sector; these workers often work in unhealthy and unsafe working environments [11], and do not have access to modern technologies that can ease their workload, which are available in developed countries [12].

In Nigeria, similar to many other developing countries, the automobile repair sector employs many informal workers. Previous studies have established a high prevalence of injuries and illnesses, such as burns, bruises, crushed digits [13], cuts, hand dermatitis, and low back pain [14], in this population [13-16]. A few studies have evaluated the impact of PWC and worker's health [13-17]; however, these studies did not indicate which of the various PWCs has the largest negative impact on worker's health. Moreover, there has been no evaluation of whether different components of PWC have a similar effect on both illnesses and injuries. Therefore, this study aims to expand the available knowledge base on the health of informal automobile repair workers (who can also be described as informally employed automotive service technicians) through an examination of the association between reported work-related illnesses or injuries and PWC. Such knowledge may potentially help policymakers and occupational health professionals to design interventions that can prevent occupational health problems among informal workers employed in the automobile industry.

\section{Materials and methods}

\subsection{Study area and population}

This cross-sectional study focuses on automobile artisans working in 3 urban areas in Osun, Nigeria: Ile-Ife, Iwo and Osogbo. In contrast to their counterparts in big cities, such as Lagos and Ibadan, who operate in well-organised automobile service centres, automobile artisans in the state of Osun mostly work in small, makeshift, roadside workplaces. Despite the informal nature of their work, almost all automobile
Table 1

Distribution of automobile artisans by trade association and town of operation

\begin{tabular}{lcccc}
\hline Trade association & Ile-Ife & Iwo & Osogbo & Total \\
\hline Mechanics & 369 & 480 & 700 & 1549 \\
Panel beaters & 294 & 348 & 400 & 1042 \\
Spray painters & 70 & 80 & 100 & 250 \\
Vulcanizers & 500 & 388 & 360 & 1248 \\
Total & 1,233 & 1,296 & 1,560 & 4,089 \\
\hline
\end{tabular}

artisans in Osun are members of a trade association. A multi-staged, random sampling technique was used to recruit study participants. The sampling frame comprised all artisans working as mechanics, panel beaters, painters or vulcanizers in the three study areas who were members of their respective trade associations. Based on the membership logs obtained from the chairmen of these trade associations, a total automobile worker population of 4,089 was identified (Table 1). Subgroup samples proportionate to each cohort were defined while adjusting for $10 \%$ nonresponse. The eligibility criteria for study inclusion specified that the workers must be currently working as master artisans, journeymen, or apprentices. Workers who had retired were excluded from the study. The first author visited the workers who were eligible for study participation at work, and informed them about the study and conveyed a recommendation from the chairman of their trade association to participate in the study.

\subsection{Data collection and methods}

The study is part of a larger doctoral study of occupational health and safety management among informal automobile artisans in Nigeria. The survey among the artisans took place between October and December 2017 after a pilot in September 2017. A semi-structured questionnaire was constructed that was based on a literature review and the responses to a prior qualitative study among the automobile artisans. The questionnaire included questions on age, education, the current position status (e.g., master, journeyman, or apprentice), length of work experience, marital status, physical working conditions, types of occupation and illnesses that can occur from the work. The questionnaire was pre-tested with 24 participants in a location different from the study locations to check the study tool's reliability and validity. The pre-test for questions on physical working conditions was deemed necessary because these were adapted from a questionnaire that was used in a developed country $[18,19]$. The pre-test identified 
the physical working conditions that are relevant to the automobile artisans in a developing country. Subsequently, only relevant PWCs were included in the final study. Face-to-face interviews were conducted by trained fieldwork assistants after obtaining the signed informed consent from the participants. During the data collection, the first author monitored and gave regular supportive supervision to the research assistants both on the spot and at the end of each day's activity to ensure the quality of the data collection process. Ethical approval for the study was obtained from the Health Research Ethics Committee, Institute of Public Health, Obafemi Awolowo University, IleIfe, Nigeria, with HREC number IPHOAU/12/764.

\subsection{Measures}

\subsubsection{Dependent variables}

The dependent variables of this study were the self-reported, work-related health problems declared by the artisans. To identify work-related health problems, the common distinction was made between work-related injuries and work-related illnesses/ diseases [20]. In the previous qualitative pilot study, participants mentioned 13 possible illnesses that could have resulted from their work activity (malaria, backache, burns, headache, cancer, eye problems, blocked cells, cough, body/leg pains, lung problems, heart problems, ulcer and stress). In the present study, this list of illnesses was presented to the respondents, who were then asked to identify which ones were familiar to them and which of the listed illness(es) they had experienced personally in the 6 months before the study. In the analysis, illnesses that had only a few positive responses were excluded because their number was too small for a robust statistical analysis (e.g. cancer had only 3 responses). Also, illnesses that were not directly related to work were excluded. For example, malaria was excluded from the analysis, because according to biomedical aetiology it is caused by a parasite transmitted by an infected mosquito which bites at night or at dusk) [21]. Moreover, according to ILO [22], a disease/illness can only be classified as occupational if the frequency of occurrence among a group of exposed workers is above the average morbidity of the rest of the population; and if there is scientific evidence of a clearly defined pattern of disease [23]. Thus, the following 6 self-reported work-related illnesses were included in the final analysis: backache, burns, headache, eye problems, body/leg pains, and stress.
The workers' experience of work-related injuries was evaluated by asking, 'Did you experience any injury at the workplace in the past six months?' The response was categorised as 'No' $=0$ or 'Yes' $=1$. In case of an affirmative answer, a follow-up question was asked ('How often?'), with the response options of 'Sometimes' $=1$ or 'Regularly' $=2$. For the purposes of the analysis, the two questions were combined to create an ordinal variable: 'No' $=0$, 'Sometimes' $=1$ and 'Regularly' $=2$.

\subsubsection{Independent variables}

The PWC was the independent variable in this study, and this was measured with the following 7 items adapted from previously validated instruments:

- 'How often do you manually lift, carry or push items heavier than $20 \mathrm{~kg}$ at least 10 times during the day?' [18],

- 'How often do you have to do repetitive movements with your hands or wrists for at least 3 hours during the day?' [18],

- 'How often do you have to work in a bent or twisted work posture?' [18],

- 'How often do you work at a height that is $2 \mathrm{~m}$ or more above the ground or floor? [19],

- 'How often do you have to continuously stand for more than 2 hours?' [19],

- 'How often do you interact with substances such as chemicals, flammable liquids and gases (e.g. exhaust fumes, petrol, paints and glues)?' [19] and

- 'How often do you suck petrol by mouth from a vehicle? [14].

The respondents were asked to rate the frequencies for each of these questions on a 3-point scale from 'Never' to 'Regularly'. Next, the number of working hours was measured by asking the respondents: 'How many hours do you work in a day?' This was measured on a 3-point scale: less than 6, 6-8 and more than 8 hours.

\subsubsection{Control variables}

Socio-demographic variables [e.g., 24] have been found to have a significant effect on workers' health in previous studies; therefore, age, length of work experience, position (master, journeyman, or apprentice), education, marital status, and occupation of the artisans were included as control variables in this study. Age was measured by asking the respondents: 'What was your age at your last birthday?' and the responses were categorised into <20, 20-30, 31-41 
and $>42$ years for ease of analysis. The length of work experience was measured with the question: 'How long have you been working?', and the response options were $<5,5-15,16-25,26-35$ and $>35$ years. However, the age categories of 26-35 and $>35$ years were combined in the analysis due to the paucity of responses.

\subsection{Statistical analysis}

A bivariate analysis was conducted to test the relationship between the dependent and independent variables. Next, the statistically significant independent variables were included in a multivariate analysis to determine the predictors of work-related health problems. Poisson regression analysis was used to examine the factors that predicted work-related illness, because the outcome variable (work-related illness) is a count variable. The ordinal logistic regression was used for work-related injury because this second outcome variable comprised ordinals. The statistical analysis was set at $P<0.05$ for all the values of Chi square and regression analysis. The incidence rate ratio (IRR) and odds ratio (OR) were reported for all study variables.

\subsubsection{Poisson regression}

A Poisson regression model assumes that the outcome variable consists of count data. Poisson regression coefficients are interpreted as the difference between the log of expected counts, which can formally be written as $\beta=\log \left(\mu x_{+1}\right)-\log (\mu x)$, where $\beta$ is the regression coefficient, $\mu$ is the expected count and the subscripts represent whether the predictor variable, say $x$, is evaluated at $x$ or $x+1$ (implying a 1-unit change in the predictor variable $x$ ).

The estimated formula is given as:

$$
\begin{aligned}
& \log (H)=\alpha+\beta_{1} X_{1}+\beta_{2} X_{2} \\
& \quad+\beta_{3} X_{3}+\beta_{4} X_{4}+\ldots \ldots \ldots+\beta_{n} X_{n}
\end{aligned}
$$

Where $H$ is the outcome variable, $\alpha_{i}$ and $\beta_{i}$ are the coefficients and $X_{i}$ are the predictor/explanatory variables. The outcome variable was the number of episodes of illness in the 6 months preceding the survey.

\subsubsection{Ordinal logistic regression}

Ordinal logistic regression is used to estimate the relationship between an ordinal outcome variable and one or more explanatory variables. The mathematical expression is:

$$
\begin{gathered}
\ln \left(\frac{\sum \operatorname{Pr}(Y \leq j / X)}{1-\sum \operatorname{Pr}(Y \leq j / X)}\right)=\propto_{j}+\beta_{i} X_{i, 1} \\
\mathrm{i}=1 \ldots \mathrm{k}, \mathrm{j}=1,2 \ldots, \mathrm{p}-1
\end{gathered}
$$

Where $\alpha_{j}$ refers to the outcome and the threshold associated with the severity of the outcome levels, $\beta_{1}$ indicates the unknown parameters to be estimated, $X_{\mathrm{i}}$ denotes the sets of explanatory variables, $i$ represents the individual, $j$ indicates the number of levels in the categorical outcome and $p$ is the number of explanatory variables.

\section{Results}

After screening, 632 (516 masters, 8 journeymen, and 108 apprentices) were enrolled into this study. A total of 21 participants from the 3 study locations refused to participate in the study; however, study interviews were continued until the required number of participants were enrolled. Table 2 shows the socio-demographic characteristics of the study participants. Age, education, marital status and position differed significantly between the occupations. However, no significant association was found between years of experience and occupation.

\subsection{Self-reported health problems among the artisans}

Table 3 shows that the majority of respondents $(88 \%)$ reported at least one work-related health problem within the preceding 6 months. The most frequently reported work-related health problems were backache/back strain, headache, and stress reported by $72.2 \%, 58.2 \%$ and $53.8 \%$ of the respondents respectively. Other problems reported were burns, body/leg pain and eye problems $(44.1 \%, 42.4 \%$ and $12.3 \%$ of the respondents, respectively). Moreover, $79.5 \%$ of the workers reported that they had experienced one or more injuries at the workplace in the 6 months preceding the survey.

The highest proportion (90.2\%) of work-related illness was reported by the automobile painters. In contrast, mechanics $(86.8 \%)$ reported more injuries than the rest of the artisans. The number of illnesses and injuries differed significantly between the worker subgroups. 
Table 2

Socio-demographic characteristics of the respondents

\begin{tabular}{lccccc}
\hline & \multicolumn{5}{c}{ Socio-demographic characteristics } \\
\cline { 2 - 6 } Characteristics & Mechanics & Panel beaters & Painters & Vulcanizers & Total \\
\hline Age & $N=235$ & $N=156$ & $N=51$ & $N=190$ & $N=632$ \\
$<20$ & $18(7.7 \%)$ & $9(5.8 \%)$ & $9(17.7 \%)$ & $26(13.7 \%)$ & $62(9.8 \%)$ \\
$20-30$ & $91(38.77 \%)$ & $47(30.1 \%)$ & $23(45.1 \%)$ & $68(35.8 \%)$ & $229(36.2 \%)$ \\
$31-41$ & $63(26.8 \%)$ & $51(32.7 \%)$ & $10(19.6 \%)$ & $43(22.6 \%)$ & $167(26.4 \%)$ \\
$>42$ & $63(26.8 \%)$ & $49(31.4 \%)$ & $9(17.7 \%)$ & $53(27.9 \%)$ & $174(27.5 \%)$ \\
\hline Education & $N=235$ & $N=156$ & $N=51$ & $N=190$ & $N=632$ \\
No formal education & $5(2.1 \%)$ & $0(0.0 \%)$ & $4(7.8 \%)$ & $2(1.1 \%)$ & $11(1.7 \%)$ \\
Primary education & $58(24.7 \%)$ & $49(31.4 \%)$ & $10(19.6 \%)$ & $59(31.1 \%)$ & $176(27.8 \%)$ \\
Secondary education & $162(68.9 \%)$ & $104(66.7 \%)$ & $29(56.9 \%)$ & $126(66.3 \%)$ & $421(66.6 \%)$ \\
Post-secondary education & $10(4.3 \%)$ & $3(1.9 \%)$ & $8(15.7 \%)$ & $3(1.6 \%)$ & $24(3.8 \%)$ \\
\hline Marital status & $N=234$ & $N=156$ & $N=51$ & $N=190$ & $N=631$ \\
Married & $169(72.2 \%)$ & $112(71.8 \%)$ & $24(47.1 \%)$ & $128(67.4 \%)$ & $433(68.5 \%)$ \\
Unmarried & $65(27.8 \%)$ & $44(28.2 \%)$ & $27(52.9 \%)$ & $62(32.6 \%)$ & $198(31.4 \%)$ \\
\hline Position & $N=235$ & $N=156$ & $N=51$ & $N=190$ & $N=632$ \\
Apprentice & $42(17.9 \%)$ & $22(14.1 \%)$ & $18(35.3 \%)$ & $34(17.9 \%)$ & $116(18.4 \%)$ \\
Master & $193(82.1 \%)$ & $134(85.9 \%)$ & $33(64.7 \%)$ & $156(82.1 \%)$ & $516(81.6 \%)$ \\
\hline Years of experience & $N=197$ & $N=135$ & $N=34$ & $N=158$ & $N=524$ \\
$<5$ & $28(14.2 \%)$ & $14(10.4 \%)$ & $4(11.8 \%)$ & $29(18.4 \%)$ & $75(14.3 \%)$ \\
5-15 & $79(40.1 \%)$ & $59(43.7 \%)$ & $20(58.8 \%)$ & $76(48.1 \%)$ & $234(44.7 \%)$ \\
16-25 & $54(27.4 \%)$ & $36(26.7 \%)$ & $8(23.5 \%)$ & $33(20.9 \%)$ & $131(25.0 \%)$ \\
$>25$ & $36(18.3 \%)$ & $26(19.3 \%)$ & $2(5.9 \%)$ & $20(12.7 \%)$ & $84(16.0 \%)$ \\
\hline
\end{tabular}

Table 3

Self-reported health problems among automobile artisans

\begin{tabular}{|c|c|c|c|c|c|c|}
\hline \multirow[t]{2}{*}{ Dependent variables } & \multicolumn{6}{|c|}{ Occupation } \\
\hline & Mechanics & Panel beaters & Painters & Vulcanizers & Total & $P$-value \\
\hline Illnesses & $N=235$ & $N=186$ & $N=51$ & $N=160$ & $N=632$ & \\
\hline 0 & $25(10.6 \%)$ & $18(11.5 \%)$ & $5(9.8 \%)$ & $28(14.7 \%)$ & $76(12.0 \%)$ & \\
\hline 1 & $33(14 \%)$ & $14(9 \%)$ & $7(13.7 \%)$ & $32(16.8 \%)$ & $86(13.6 \%)$ & 0.01 \\
\hline 2 & $27(11.5 \%)$ & $23(14.7 \%)$ & $6(11.8 \%)$ & $38(20 \%)$ & $94(14.9 \%)$ & \\
\hline 3 & $51(22 \%)$ & $26(16.7 \%)$ & $14(27.5 \%)$ & $31(16.3 \%)$ & $122(19.3 \%)$ & \\
\hline 4 & $53(22.6 \%)$ & $33(21.2 \%)$ & $15(29.4 \%)$ & $40(21.1 \%)$ & $141(22.3 \%)$ & \\
\hline 5 & $39(16.6 \%)$ & $35(22.4 \%)$ & $4(7.8 \%)$ & $15(7.9 \%)$ & $93(14.7 \%)$ & \\
\hline 6 & $7(3 \%)$ & $7(4.5 \%)$ & - & $6(3.2 \%)$ & $20(3.2 \%)$ & \\
\hline Injuries & $N=234$ & $N=156$ & $N=51$ & $N=189$ & $N=630$ & \\
\hline No & $31(13.2 \%)$ & $31(19.9 \%)$ & $20(39.2 \%)$ & $47(24.9 \%)$ & $129(20.5 \%)$ & 0.00 \\
\hline Sometimes & $157(67.1 \%)$ & $105(67.3 \%)$ & $25(49.0 \%)$ & $127(67.2 \%)$ & $414(82.6 \%)$ & \\
\hline Regularly & $46(19.7 \%)$ & $20(12.8 \%)$ & $6(11.8 \%)$ & $15(7.9 \%)$ & $87(17.4 \%)$ & \\
\hline
\end{tabular}

\subsection{Association between occupation and independent variables}

The differences in illnesses and injuries between the occupational subgroups may be related to differences in exposure to harmful work conditions. Table 4 shows that a majority of panel beaters $(70.5 \%)$ reported regular manual lifting of heavy items at least 10 times per day, compared to only a third of the painters (29.4\%). The majority of workers in all study groups reported that they regularly carried out activities with repetitive movements of hands/wrists for at least 3 hours during the day (70\%), worked in a bent position (82\%), continuously stood for more than 2 hours $(61 \%)$, worked for more than 8 hours a day $(60 \%)$ and encountered substances such as chemicals and flammable liquids (72\%). Five items differed significantly between the subgroups by occupations: manual lifting of heavy objects, working at $2 \mathrm{~m}$ above the ground level, continuously standing for more than 2 hours, encountering chemicals and orally sucking petrol. A greater proportion of mechanics reported regularly sucking petrol by mouth compared to the rest of the groups (69\%). The majority of workers reported that they never worked at a height of more than $2 \mathrm{~m}$ above the ground level (49\%). 
Table 4

Association between occupation and independent variables

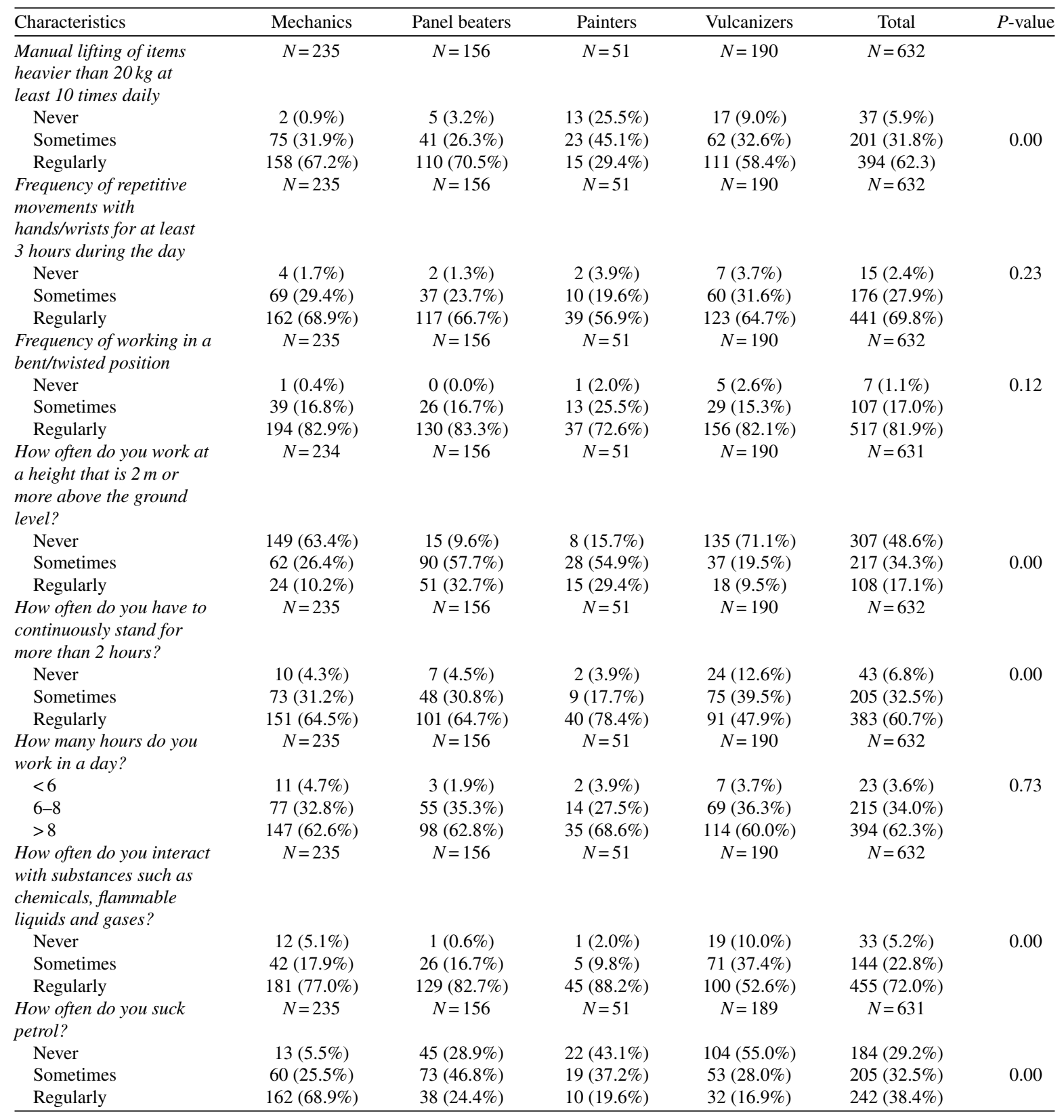

\subsection{Relationship between physical work conditions and work-related illnesses}

The results of Poisson regression analysis on the effects of the independent variables on self-reported illnesses are presented in Table 5. Bivariate analysis and the joint effect of the independent variables on self-reported illnesses are both shown. Only variables that were significant in the bivariate analysis were included in the final multivariate analysis. Therefore, only age, work experience and occupation were used as the control variables.

The bivariate analysis showed that the respondents who sometimes or regularly lifted heavier items, undertook repetitive movements with their hands, worked in a bent/twisted position, worked at a height of at least $2 \mathrm{~m}$ above the ground level, continuously stood for more than 2 hours or orally sucked petrol 
Table 5

Relationship between physical work conditions and work-related illness

\begin{tabular}{|c|c|c|c|c|}
\hline \multicolumn{5}{|c|}{ Number of self-reported illnesses } \\
\hline \multirow[b]{2}{*}{ Explanatory variables } & \multicolumn{2}{|c|}{ Bivariate analysis } & \multicolumn{2}{|c|}{ Multivariate analysis } \\
\hline & IRR & $P$-value & IRR & $P$-value \\
\hline \multicolumn{5}{|l|}{ Manual lifting of items } \\
\hline \multicolumn{5}{|c|}{ heavier than $20 \mathrm{~kg}$ at least } \\
\hline \multicolumn{5}{|c|}{10 times daily } \\
\hline Never & $\mathrm{RC}$ & & $\mathrm{RC}$ & \\
\hline Sometimes & 1.769 & 0.00 & 1.470 & 0.01 \\
\hline Regularly & 2.493 & 0.00 & 1.726 & 0.00 \\
\hline \multicolumn{5}{|l|}{ Frequency of repetitive } \\
\hline \multicolumn{5}{|c|}{ hands/wrists for at least 3} \\
\hline \multicolumn{5}{|c|}{ hours during the day } \\
\hline Never & $\mathrm{RC}$ & & $\mathrm{RC}$ & \\
\hline Sometimes & 1.473 & 0.02 & 1.178 & 0.39 \\
\hline Regularly & 1.686 & 0.00 & 0.955 & 0.81 \\
\hline \multicolumn{5}{|c|}{ Frequency of working in a } \\
\hline \multicolumn{5}{|l|}{ bent/twisted position } \\
\hline Never & $\mathrm{RC}$ & & $\mathrm{RC}$ & \\
\hline Sometimes & 2.191 & 0.00 & 1.698 & 0.11 \\
\hline Regularly & 2.813 & 0.00 & 1.730 & 0.09 \\
\hline \multicolumn{5}{|c|}{ How often do you work at a } \\
\hline \multicolumn{5}{|c|}{ height that is $2 m$ or more } \\
\hline \multicolumn{5}{|l|}{ above ground level? } \\
\hline Never & $\mathrm{RC}$ & & $\mathrm{RC}$ & \\
\hline Sometimes & 1.577 & 0.00 & 0.975 & 0.68 \\
\hline Regularly & 1.372 & 0.00 & 0.775 & 0.00 \\
\hline \multicolumn{5}{|c|}{ How often do you have to } \\
\hline \multicolumn{5}{|c|}{ continuously stand for } \\
\hline more than 2 hours? & & & & \\
\hline Never & $\mathrm{RC}$ & & $\mathrm{RC}$ & \\
\hline Sometimes & 1.303 & 0.01 & 0.987 & 0.91 \\
\hline Regularly & 1.740 & 0.00 & 1.007 & 0.95 \\
\hline How many hours do yo & & & & \\
\hline in a day? & & & & \\
\hline$<6$ & $\mathrm{RC}$ & & $\mathrm{RC}$ & \\
\hline $6-8$ & 1.280 & 0.15 & 1.077 & 0.71 \\
\hline$>8$ & 2.127 & 0.00 & 1.757 & 0.00 \\
\hline How often do you inter & & & & \\
\hline with substances such a & & & & \\
\hline chemicals, flammable & & & & \\
\hline liquids, and gases? & & & & \\
\hline Never & $\mathrm{RC}$ & & $\mathrm{RC}$ & \\
\hline Sometimes & 1.064 & 0.58 & 0.801 & 0.09 \\
\hline Regularly & 1.841 & 0.00 & 0.978 & 0.86 \\
\hline How often do you suck & & & & \\
\hline Never & $\mathrm{RC}$ & & $\mathrm{RC}$ & \\
\hline Sometimes & 2.023 & 0.00 & 1.558 & 0.00 \\
\hline Regularly & 3.626 & 0.00 & 2.157 & 0.00 \\
\hline Age (years) & & & & \\
\hline$<20$ & $\mathrm{RC}$ & & $\mathrm{RC}$ & \\
\hline $20-30$ & 1.316 & 0.00 & 1.076 & 0.75 \\
\hline $31-41$ & 1.211 & 0.04 & 0.953 & 0.84 \\
\hline$>42$ & 1.268 & 0.01 & 0.883 & 0.61 \\
\hline Work experience (year & & & & \\
\hline$<5$ & $\mathrm{RC}$ & & $\mathrm{RC}$ & \\
\hline $5-15$ & 1.125 & 0.16 & 1.163 & 0.09 \\
\hline $16-25$ & 1.367 & 0.00 & 1.388 & 0.00 \\
\hline$>25$ & 1.483 & 0.00 & 1.652 & 0.00 \\
\hline
\end{tabular}


Table 5

(Continued)

\begin{tabular}{|c|c|c|c|c|}
\hline \multirow[b]{3}{*}{ Explanatory variables } & \multicolumn{4}{|c|}{ Number of self-reported illnesses } \\
\hline & \multicolumn{2}{|c|}{ Bivariate analysis } & \multicolumn{2}{|c|}{ Multivariate analysis } \\
\hline & IRR & $P$-value & IRR & $P$-value \\
\hline \multicolumn{5}{|l|}{ Education } \\
\hline No formal education & $\mathrm{RC}$ & & & \\
\hline Primary education & 0.951 & 0.78 & - & - \\
\hline Secondary education & 1.027 & 0.88 & & \\
\hline Post-secondary education & 0.977 & 0.92 & & \\
\hline \multicolumn{5}{|l|}{ Marital status } \\
\hline Married & $\mathrm{RC}$ & & - & - \\
\hline Unmarried & 0.990 & 0.85 & & \\
\hline \multicolumn{5}{|l|}{ Position } \\
\hline Apprentice & $\mathrm{RC}$ & & - & - \\
\hline Master & 1.095 & 0.14 & & \\
\hline \multicolumn{5}{|l|}{ Occupation } \\
\hline Mechanic & $\mathrm{RC}$ & & $\mathrm{RC}$ & \\
\hline Panel beater & 1.065 & 0.29 & 1.194 & 0.03 \\
\hline Painter & 0.943 & 0.53 & 1.117 & 0.39 \\
\hline Vulcanizer & 0.847 & 0.01 & 0.907 & 0.22 \\
\hline
\end{tabular}

*Note: $I R R=$ incidence rare ratio RC = reference category.

were more likely to report work-related illnesses than workers who never undertook these tasks. Moreover, workers who worked more than 8 hours per day reported more illnesses than those who worked less than 6 hours (IRR $=2.1, p=0.00$ ), whereas workers who regularly encountered chemicals were more likely to report illnesses than those who never worked with chemicals (IRR $=1.8, p=0.00)$. Workers older than 20 years were more likely to report illnesses than younger workers. Moreover, the longer the work experience, the greater the number or episodes of illnesses reported. Lastly, vulcanizers were less likely to report illness compared to mechanics (IRR $=0.8$, $p=0.01$ ).

The results of multivariate analysis show that workers who manually lifted heavy items (IRR $=1.7$, $p=0.00)$, orally sucked petrol ( $\operatorname{IRR}=2.2, p=0.00)$, worked longer hours per day (IRR $=1.8, p=0.00$ ) or had been working for a longer period (IRR $=1.7$, $p=0.00$ ) were more likely to report illnesses. Furthermore, panel beaters were more likely to report illnesses than mechanics. Lastly, counterintuitively, the analysis showed that workers who regularly worked at a height of more than $2 \mathrm{~m}$ above the ground level were less likely to report illnesses.

\subsection{Relationship between physical work conditions and work-related injuries}

Table 6 shows the results of both the bivariate and multivariate ordinal regression analyses of workrelated injuries. Repetitive hand movements and the number of work hours in a day did not show any significant relationship at the bivariate level; therefore, they were excluded from the multivariate analysis. Education and position were not included as control variables for the same reason.

The joint effect of the independent variables on work-related injuries with the age, work experience, marital status and occupation of the workers as control variables showed that workers who lifted heavy objects $(\mathrm{OR}=4.8, p=0.00)$, stood continuously for more than 2 consecutive hours while working $(\mathrm{OR}=2.2, p=0.05)$ or orally sucked petrol $(\mathrm{OR}=9.1, p=0.00)$ were more likely to report work-related injury. However, workers who regularly worked at a height of $2 \mathrm{~m}$ or higher above the ground level were less likely to report work-related injury ( $\mathrm{OR}=0.5, p=0.02)$. Lastly, painters were less likely to report work-related injuries compared with mechanics.

When the other variables were included, working in a bent/twisted position and exposure to chemical substances were no longer statistically significant at $p<0.05$.

\section{Discussion}

This study explored the effect of PWC on perceived work-related health problems among informal automobile artisans in Osun State, Nigeria. A high prevalence of work-related health problems was identified, with $88 \%$ of the respondents reporting at least 
Table 6

Relationship between physical work conditions and injuries

\begin{tabular}{|c|c|c|c|c|}
\hline \multicolumn{5}{|c|}{ Number of self-reported injuries } \\
\hline \multirow[b]{2}{*}{ Explanatory variables } & \multicolumn{2}{|c|}{ Bivariate analysis } & \multicolumn{2}{|c|}{ Multivariate analysis } \\
\hline & OR & $P$ value & OR & $P$ value \\
\hline \multirow{3}{*}{\multicolumn{5}{|c|}{$\begin{array}{l}\text { Manual lifting of items } \\
\text { heavier than } 20 \mathrm{~kg} \text { at least } \\
10 \text { times daily }\end{array}$}} \\
\hline & & & & \\
\hline & & & & \\
\hline Never & $\mathrm{RC}$ & & $\mathrm{RC}$ & \\
\hline Sometimes & 8.432 & 0.00 & 6.071 & 0.00 \\
\hline Regularly & 9.733 & 0.00 & 4.759 & 0.00 \\
\hline \multicolumn{5}{|l|}{ Frequency of repetitive } \\
\hline \multicolumn{5}{|l|}{ movements with } \\
\hline \multicolumn{5}{|c|}{ hands/wrists for at least 3} \\
\hline \multicolumn{5}{|l|}{ hours during the day } \\
\hline Never & $\mathrm{RC}$ & & & \\
\hline Sometimes & 0.940 & 0.92 & - & - \\
\hline Regularly & 1.094 & 0.88 & & \\
\hline \multicolumn{5}{|c|}{ Frequency of working in a } \\
\hline \multicolumn{5}{|l|}{ bent/twisted position } \\
\hline Never & $\mathrm{RC}$ & & $\mathrm{RC}$ & \\
\hline Sometimes & 9.630 & 0.01 & 4.620 & 0.11 \\
\hline Regularly & 7.193 & 0.02 & 3.031 & 0.23 \\
\hline \multicolumn{5}{|c|}{ How often do you work at a } \\
\hline \multicolumn{5}{|c|}{ height that is $2 m$ or more } \\
\hline \multicolumn{5}{|c|}{ above ground level? } \\
\hline Never & $\mathrm{RC}$ & & $\mathrm{RC}$ & \\
\hline Sometimes & 1.696 & 0.01 & 1.229 & 0.37 \\
\hline Regularly & 0.753 & 0.25 & 0.501 & 0.02 \\
\hline \multicolumn{5}{|c|}{ How often do you have to } \\
\hline \multicolumn{5}{|c|}{ continuously stand for } \\
\hline \multicolumn{5}{|l|}{ more than 2 hours? } \\
\hline Never & $\mathrm{RC}$ & & $\mathrm{RC}$ & \\
\hline Sometimes & 2.113 & 0.05 & 1.614 & 0.26 \\
\hline Regularly & 3.746 & 0.00 & 2.217 & 0.05 \\
\hline How many hours do yo & & & & \\
\hline in a day? & & & & \\
\hline$<6$ & $\mathrm{RC}$ & & & \\
\hline $6-8$ & 0.476 & 0.14 & - & - \\
\hline$>8$ & 0.910 & 0.85 & & \\
\hline How often do you inter & & & & \\
\hline with substances such a & & & & \\
\hline chemicals, flammable & & & & \\
\hline liquids and gases? & & & & \\
\hline Never & $\mathrm{RC}$ & & $\mathrm{RC}$ & \\
\hline Sometimes & 0.473 & 0.32 & 0.491 & 0.14 \\
\hline Regularly & 4.957 & 0.01 & 0.836 & 0.71 \\
\hline How often do you suck & & & & \\
\hline Never & $\mathrm{RC}$ & & $\mathrm{RC}$ & \\
\hline Sometimes & 2.538 & 0.01 & 3.778 & 0.00 \\
\hline Regularly & 13.397 & 0.00 & 9.114 & 0.00 \\
\hline Age (years) & & & & \\
\hline$<20$ & $\mathrm{RC}$ & & $\mathrm{RC}$ & \\
\hline $20-30$ & 2.261 & 0.01 & 1.662 & 0.57 \\
\hline $31-41$ & 2.374 & 0.01 & 1.652 & 0.59 \\
\hline$>42$ & 3.278 & 0.00 & 1.857 & 0.51 \\
\hline Work experience (year & & & & \\
\hline$<5$ & $\mathrm{RC}$ & & $\mathrm{RC}$ & \\
\hline $5-15$ & 1.086 & 0.77 & 1.042 & 0.89 \\
\hline $16-25$ & 1.721 & 0.09 & 1.217 & 0.59 \\
\hline$>25$ & 2.125 & 0.03 & 1.645 & 0.25 \\
\hline
\end{tabular}


Table 5

(Continued)

\begin{tabular}{|c|c|c|c|c|}
\hline \multicolumn{5}{|c|}{ Number of self-reported injuries } \\
\hline \multirow[b]{2}{*}{ Explanatory variables } & \multicolumn{2}{|c|}{ Bivariate analysis } & \multicolumn{2}{|c|}{ Multivariate analysis } \\
\hline & OR & $P$ value & OR & $P$ value \\
\hline \multicolumn{5}{|l|}{ Education } \\
\hline No formal education & $\mathrm{RC}$ & & & \\
\hline Primary education & 0.488 & 0.30 & & \\
\hline Secondary education & 0.645 & 0.53 & - & - \\
\hline Post-secondary education & 1.047 & 0.96 & & \\
\hline \multicolumn{5}{|l|}{ Marital status } \\
\hline Married & $\mathrm{RC}$ & & $\mathrm{RC}$ & \\
\hline Unmarried & 0.596 & 0.01 & 0.824 & 0.52 \\
\hline \multicolumn{5}{|l|}{ Position } \\
\hline Apprentice & $\mathrm{RC}$ & & & \\
\hline Master & 1.534 & 0.06 & - & - \\
\hline \multicolumn{5}{|l|}{ Occupation } \\
\hline Mechanic & $\mathrm{RC}$ & & $\mathrm{RC}$ & \\
\hline Panel beater & 0.608 & 0.02 & 0.596 & 0.08 \\
\hline Painter & 0.276 & 0.00 & 0.284 & 0.01 \\
\hline Vulcanizer & 0.429 & 0.00 & 0.619 & 0.08 \\
\hline
\end{tabular}

*Note: OR $=$ odd ratio; $R C=$ reference category.

one illness in the 6 months preceding the study, and almost $80 \%$ of study participants having experienced injury at some point in time. These findings corroborate the findings of Johnson et al. [14], who reported that automobile artisans in Uyo, Nigeria reported a high incidence of health problems.

The findings of this study indicate that PWC are more strongly associated with work-related illnesses than with work-related injuries. This association between PWC and work-related illness is in accordance with previous studies that reported PWC to be a risk factor for health problems among informal workers [11]. Schreuder et al. [4] found that higher physical work demands among blue collar workers were associated with higher rates of low back pain, headaches, cardiac pain and drowsiness. However, only a few of the PWC were found to have a significant association with work-related injuries in this study (manual lifting of heavy objects and continuously standing for more than 2 hours). Arguably, the cumulative effects of PWC can lead to work-related illnesses in workers, whereas the effects of injuries are likely to be more acute. For instance, a worker who is carrying a heavy object can be injured instantly, whereas the same activity without acute injury can lead to musculoskeletal disorders over time.

Furthermore, it is interesting that the rates of both self-reported accidents and illnesses are high, which therefore shows possible factors that are particularly associated with illness. This is remarkable because other reports [20] show that the rates of work-related accidents/injuries are particularly high in Africa, and there is a probability that a work-related incident reported from this region is more likely to be in relation to an accident rather than an illness.

With regard to the exposure of workers to chemical substances, only orally sucking petrol showed a significant relationship with both illness and injury. Previous studies have reported that sucking petrol is a work practice common among roadside automobile artisans, especially among mechanics. For example, Johnson et al. [14] found that three quarters of workers in their study population orally sucked petrol. They suggested that constant interaction with fuel could be responsible for the numerous adverse health outcomes among automobile artisans in Rivers State, Nigeria.

The present study found that workers who worked more than 8 hours per day reported more illnesses. This is consistent with the growing body of evidence that indicates a negative impact of long working hours on worker's health [7]. Working long hours each day could be responsible for work-related illnesses reported by the workers ( $88 \%$ ); however, no association was found between working longer hours and work-related injury.

Furthermore, the analysis found a strong association between working for more than 16 years and illnesses. Workers who had worked between 16 and 25 years $(\operatorname{IRR}=1.4, p=0.00)$ and $>25$ years (IRR $=1.7, p=0.00)$ were more likely to report workrelated illnesses. This suggests that the longer a worker has been subject to unfavourable PWC, the greater the number of worker-reported work-related 
illness. This finding is in agreement with the results of Jazari et al. [24], who reported a significant association between workers' health and work experience. Moreover, this could be a clear indication of a cumulative effect of PWC on workers' health over the years. However, no association was found between work experience and injury. This may be attributable to the fact that the relationship between PWC and injuries is a more acute problem.

In addition, this study presents interesting findings on the occupation of workers and their self-reported illness and injury. As the occupation was still significant after including a large number of specific PWCs, it appears that other unobserved working conditions could lead to work-related health problems, and this appears to apply more to illnesses than to injuries. Therefore, future research should try to establish which other working conditions are related to workplace health problems in various occupations.

Lastly, contrary to expectations, the present study found a negative association between regularly working at a height of more than $2 \mathrm{~m}$ above the ground level and injury/illness. A plausible explanation for this could be that workers may have gained expertise in working at heights due to the high frequency at which they undertake the activity; alternatively, the workers may be using a stable object to stand on while carrying out the activity, which reduces the risk of falling. Moreover, it could be that workers who reported working at heights are tall, and thereby have a lower risk of injury. Finally, regularly working at heights could prevent the artisans from working in awkward postures that could affect their health.

\subsection{Strengths and limitations}

A limitation of this study is its cross-sectional design. Therefore, the evidence may be inadequate to draw strong conclusions about the relationships between various factors and work-related illnesses or injuries. For example, even though artisans who worked at heights were found to report fewer health problems than others, this result is based on a onetime self-reported measurement. Further studies are needed to identify cause and effect with regard to workers' health. Moreover, the study was based on self-report and retrospective questions which may affect the reliability of the answers. A strength of this study is that it presents the relationship between PWC and work-related health problems among informal workers in a low-income country.

\section{Conclusions}

Despite the differences in physical working conditions, informal automobile workers in developing countries reported similar work-related health problems as workers who are formally employed in high-income countries. The findings of the present study may help relevant stakeholders to identify the work conditions that workers themselves can change and the conditions that are beyond the control of the artisans. For example, access to lifting equipment that can reduce manual lifting of heavy equipment could be beyond the control of the workers, probably because such equipment may be too expensive for the workers to purchase. The government could then provide equipment at subsidised rates for workers. On the other hand, orally sucking petrol and managing stress are work conditions that the workers can control by themselves. Therefore, training programs that can educate artisans on the deleterious effect of orally sucking petrol, working without adequate rest and ineffective customer management (which can lead to time pressure and stress) might be helpful.

In conclusion, interventions by occupational health professionals, policymakers and researchers to reduce work-related illness and injury should focus on the reduction of manual lifting of heavy items and oral sucking of petrol among automobile artisans.

\section{Acknowledgments}

The first author received a grant (\#DVC/AC/ 37A/AFO) from the Tertiary Education Trust Fund (TETFUND) under the Academic Staff Training and Development Program for her Doctor of Philosophy studies at the University of Amsterdam, The Netherlands. TETFUND was not involved in the study design, data collection, analysis, and interpretation or reporting of the data.

\section{Conflict of interest}

None to report.

\section{References}

[1] Takala J, Urrutia M, Hämäläinen P, Saarela KL. The global and European work environment - numbers, trends, and strategies. SJWEH Suppl. 2009;(7):15-23. 
[2] Salminen S. Long working hours and shift work as risk factors for occupational injury. The Ergonomics Open J. 2018;11(9):15-26.

[3] Jørgensen MB, Korshøj M, Lagersted-Olsen J, Villumsen M, Mortensen OS, Skotte J, Madeleine KP, Thomsen BL, Holtermann A. Physical activities at work and risk of musculoskeletal pain and its consequences: protocol for a study with objective field measures among bluecollar workers. BMC Musculoskelet Disord. 2013;14(213). https://doi.org/10.1186/1471-2474-14-213.

[4] Schreuder KJ, Roelen CAM, Koopmans PC, Groothoff JW. Job demands and health complaints in white and blue collar workers. Work. 2008;31:425-32.

[5] Karlqvist LK, Härenstam A, Leijon O, Schéele P; MOA Research group. Excessive physical demands in modern work life and characteristics of work and living conditions of persons at risk. Scand J Work Environ Health. 2003;29(5):363-77.

[6] Kim K, Won YL, Ko K, Chung YH. The effects of hazardous chemical exposure on cardiovascular disease in chemical products manufacturing workers. Toxicol Res. 2012;28(4):269-77.

[7] Persaud H, Williams S. Long working hours and occupational stress-related illness and injury: Mini review. J Health Sci Educ. 2017;1(3):1-4.

[8] Bannai A, Tamakoshi A. The association between long working hours and health: A systematic review of epidemiological evidence. Scand J Work Environ Health. 2014;40(1):5-18.

[9] Schnall PL, Dobson M, Rosskam E, Elling RH. Unhealthy Work. New York: Routledge; 2018.

[10] Loayza NV. Informality in the process of development and growth. Policy research working paper 7858 World Bank group, Development Research Group, Macroeconomics and growth team Oct 2016 [cited 2019 Jun 30]. Available from: http://pubdocs.worldbank.org/en/278451476349329 578/Informality-in-the-Process-of-Development-NormanLoayza.pdf.

[11] Rockefeller Foundation. Health vulnerabilities of informal workers. May 2013 [cited 2016 Mar 06]. Available from: https://www.rockefellerfoundation.org/report/healthvulnerabilities-of-informal-workers/.

[12] Ikeije UI, Akomolafe L, Onuba CO. Labour practices in the informal sector of Nigerian economy: A critical analysis. Glob J Arts Humanit Soc Sci. 2016;4(2):6-14.

[13] Sambo MN, Idris SH, Shamang A. Determinants of occupational health hazards among roadside automobile mechanics in Zaria, North Western Nigeria. Borno Med J. 2012;9(1): 5-9.
[14] Johnson OE, Bassey EA. Work habits and health problems of automobile technicians at mechanic village, Uyo, Nigeria. Glob Adv Res J Med Sci. 2016;5(5):136-42.

[15] Adeyemi HO, Akinyemi AI, Musa AI, Ibikunle BQ. Assessment of work-space and work-method designs in Nigeria Automobile service repair industry. Niger J Technol. 2016;35(2) 321-8.

[16] Elenwo EI. Occupational hazards and risks of automobile mechanics in Port Harcourt Metropolis, Rivers State, Nigeria. Int J Health, Safety Environ. 2018;4(01):156-67.

[17] Adejumo M, Olaiya YV, Sridhar MKC. Blood lead levels among automobile mechanics in a megacity, Lagos, Nigeria. Int J Health Sci. 2017;5(2):17-27.

[18] Kausto J, Miranda H, Pehkonen I, Heliovaara M, ViikariJuntura E, Solovieva S. The distribution and co-occurrence of physical and psychological risk factors for musculoskeletal disorders in a general working population. Int Arch Occup Environ Health. 2011;84(7):773-88.

[19] Smith PM, Saunders R, Lifshen M, Black O, Lay M, Breslin FC, LaMontagne AD, Tompa E. The development of a conceptual model and self-reported measure of occupational health and safety vulnerability. Accid Anal Prev. 2015;82:234-43.

[20] Hämäläinen P. Global Estimates of Occupational Accidents and Fatal Work-Related Diseases. Doctoral dissertation, Publication 917, Tampere University of Technology, Finland; 2010 [cited: 06-12-2019 ]. Available from: http:// dspace.cc.tut.fi/dpub/bitstream/handle/123456789/6818/ha malainen.pdf? sequence $=1$

[21] https://www.nhs.uk/conditions/malaria/causes/ Accessed on 13-08-2018.

[22] International Labour Organization. List of occupational diseases. Available from: https://www.mhlw.go.jp/stf/shingi/ 2r98520000033ssx-att/2r98520000033sz1.pdf. Accessed: 18-02-2021

[23] Tjalvin G. Work-related and occupational diseases. Available from: https://www.futurelearn.com/info/courses/ occupational-health-developing-countries/0/steps/13078. Accessed: 18-02-2021.

[24] Jazari MD, Jahangiri M, Khaleghi H, Abbasi N, Hassanipour S, Shakerian M, Kamalinia M. Prevalence of self-reported work-related illness and injuries among building construction workers, Shiraz, Iran. EXCLI J. 2018;17:724-33. 